\title{
Results of the Biochemical Study of Mandarin (Citrus reticulata Blanco) Mutants
}

G.R. Memarne, N.I. Khalvashi, M.T. Gabaidze, D. Sh. Baratashvili, A.R. Kalandia', M.G. Vanidze', I.O. Kartsivadze ${ }^{1}$

10.18805/IJARe.A-591

\begin{abstract}
Background: Induced mutagenesis has been used in citrus breeding, in Georgia, since 1960, resulting in many interesting and promising mutant forms that require morphological, physiological and biochemical studies. The present paper presents the results of biochemical research of some promising mutants.

Methods: During the period 2017-2019 investigate on 13 promising mutant forms of mandarin has been carried out. In the current study, phenolic composition-content in the fruits of mandarin mutants were determined using Ultraviolet Spectrophotometer and High Performance Liquid Chromatography (HPLC) and their antioxidant capacities were evaluated using 2.2-diphenyl-1-picrylhydrazyl (DPPH) radicals.

Result: The results have shown that different concentrations of mutagen effect on mandarin seeds and, accordingly, on the biochemical components which they include. In most cases, this leads to a positive result. The impact of the mutagen significantly increases the range of changes in biochemical components and varies over a wide range. Analyzing the data, we can conclude that the solutions of all concentrations of the Nash mutagen effect a change in the biochemical indicators in mutant forms. However, a wide range of variability is largely associated with the use of medium and low concentrations of the mutagen. In most cases, the majority of mutant forms significantly outperform the control variants in the content of biochemical components. The study has revealed a variety of mutant forms (gene pool), which characterized a whole complex of positive signs. Their use in selection allows getting perspective forms with positive features.
\end{abstract}

Key words: Antioxidant activity, Citrus, Flavonoids, Mutagenesis, Mutants, Phenolic acids.

\section{INTRODUCTION}

In recent years, because of an increased interest in human health, nutrition and disease prevention, consumers have increased their demand for functional foods including fruits and their products. Among various natural healthy fruits, citrus fruits prevail abundantly around the world and mandarins are among the most popular citrus fruits (Peterson et al., 2006).

Citrus occupies a special place in the global economy in terms of food and trade. The literary sources state that citrus fruits are rich in organic acids, vitamins, phenolic compounds, flavonoids and antioxidants, which reduce the risk of developing cardiovascular, neurological, various chronic and degenerative diseases and also hinder the development of cancer cell growth (Watada et al., 1990, Gil et al., 2000, Gil-Izquierdo et al., 2001, Bermejo et al., 2011, Masayoshi et al., 2004, Del Caro et al., 2004). If we look into the history of the origin of citrus industrial varieties, we can see that the most varieties (more than $80 \%$ ) are the result of spontaneous (natural) mutations and are caused by the mutation of the plant buds (Tanaka, 1925). Despite the fact that spontaneous (natural) mutational processes play an important role in improving the varieties of citrus, it should be noted that under natural conditions mutations occur quite rarely, and the induced mutational processes make it possible for changes to occur with such frequency
Department of Biodiversity Monitoring and Conservation, Institute of Phytopathology and Biodiversity, Batumi Shota Rustaveli State University, Georgia.

'Department of Analytical Chemistry and Food Product Safety, Institute of Agrarian and Membrane Technologies, Shota Rustaveli State University, Georgia.

Corresponding Author: G.R. Memarne, Institute of Phytopathology and Biodiversity, Batumi Shota Rustaveli State University, Georgia. Email: plantimmunity@yahoo.com

How to cite this article: Memarne, G.R., Khalvashi, N.I., Gabaidze, M.T., Baratashvili, D.Sh., Kalandia, A.R., Vanidze, M.G. and Kartsivadze, I.O. (2021). Results of the Biochemical Study of Mandarin (Citrus reticulata Blanco) Mutant. Indian Journal of Agricultural Research. 55(5): 535-541. DOI: 10.18805/IJARe.A-591.

Submitted: 22-08-2020 Accepted:22-03-2021 Online: 29-04-2021

that the results of selection, thus obtained, often prevail over the results of clone selection and hybridization. Chemical agents contribute not only to the increase in the frequency of mutations but due to them, rare beneficial mutants can be obtained that are not formed in natural conditions. Acceleration of the mutation process by induction expands the selection force and creates the possibility of a targeted choice of industrially valuable mutants. Many promising varieties, such as grapefruit "Star Rub" and "Rio Ready", lemon "Eureka 22INTA", orange "Valencia 22 INTA" and 
others, are also obtained by induced mutagenesis (Maluszynski et al., 2000).

The first artificial mutation was performed on Citrus seeds using the x-rays by Haskin and Moore in 1935 (Cameron, 1968). The subsequent applications of artificial mutations were carried out to impro-ve some properties of seedless mandarin (Sutarto et al., 2009).

According to FAO/IAEA, the number of varieties, grown under the influence of induced mutagenesis, is rapidly increasing in the world. According to the data of 1969, 77 mutant varieties were obtained by mutagenesis, in 1989 this figure increased to 1330 and in 2009 the number of mutant varieties increased to 3200 . From literary sources (Micke et al.,1987), it is known that most of the varieties, obtained as a result of induced mutagenesis, come from China and India, although many types of crops, obtained in this way, are also bred in other countries (Netherlands, USA, Japan, Bulgaria and others). According to the data of Bulgarian scientists (Tomlekova, 2010), in Bulgaria the following number of perspective varieties was obtained by induced mutagenesis: barley-5, wheat-5, durum-9, corn-26, sunflower seeds -3 , soybean-2, peas -1 , tomato- 6 , pepper- 4 , tobacco-2.

Georgian breeders have carried out large-scale work in this direction. They developed methods for the effects of various mutagens (nitrosomethyl urea, dimethyl sulfate, nitrosoethyl urea, ethyleneimine, 1.4 diazo-acetyl betadine and others) on seedlings, cuttings, peel, germ, pollen and seeds of subtropical fruit trees.

Many interesting mutants have been obtained under the influence of chemical mutagens. The viability of some chemical mutagens was confirmed and the method of treating seeds, cuttings, fibers and pollen by various mutagens was developed as well. Optimal dosages and exposures were refined. Long-term studies have shown that the use of chemical mutagens is particularly promising in citrus selection. During this period, an extensive gene pool of mutants with pronounced useful agricultural properties were created in Georgia (Goliadze, 1989, Kerkadze, 1984, Diasamidze, 1994).

It has been established that various mutagens and their different dosages react differently to different cultures and varieties. Along with changes in life processes, there is a significant increase in the hereditary variability of the organism, the frequency and range of mutations. The given paper presents an analysis of the effect of nitrosoethyl urea mutagen on the seeds of the mandarin "Unshiu", obtained by free pollination, as well as the biochemical components of the fetus.

\section{MATERIALS AND METHODS}

The object of the study is a mandarin variety "Unshiu" - Citrus reticulata Blanco "Unshiu" (Cottin, 2002), brought from Japan in 1929 and spread so quickly in Georgia, that today it occupies almost $90 \%$ of industrial citrus plantations of Georgia.
The use of induced mutagenesis in citrus and tea crops began in Georgia in 1960. We have treated mandarin seeds with mutagen in 1999-2000 at a Research Institute of Subtropical Crops and the Tea Industry. The biochemical components (organic acids, sugars, phenolic compounds, flavonoids and antioxidant activity) of a mutant form of the mandarin "Unshiu" fruits has been studied at the Department of Chemical Analysis and Food Safety of Batumi Shota Rustaveli State University's Agrarian and Membrane Technology Institute and at West Georgia Chromatography Centerstudied in 2017-2019.

The biochemical indicators of mutant forms were compared with two control variants, considering the effect of mutagen on seeds, the spectrum of variability and the specifics of the experiment.

Control 1- Vegetatively propagation mandarin (Citrus reticulata Blanco "Unshiu", as rootstock was used Trifoliate [Poncirus trifoliate (L) Raf].

Control 2- Nucellar seedling of mandarine "Unishu". The seeds were processed in distilled water.The seeds were removed from the mandarin "Unshiu" fruits. Because the mandarin fruits ovaring without prior fertilization (a process known as parthenocarpy) under normal conditions they do not produce seeds. To obtain a large number of seeds for analysis, four types of biologically distinct citruses were used for fertilization: Ichangensis (Citrus Ichangensis Swingle), the orange [Citrus sinensis (L) Osbeck], Pomelo [Citrus maxima (Burm)] and the mandarin Shiva-Mikan (Citrus leiokarpa Tan).

Mutagen nitrosoethyl urea was used in seed treatment to obtain selective material and get a mutagenic effect in mandarin:

$$
\begin{array}{cc}
\mathrm{CH}_{3}-\mathrm{CH}_{2}-\mathrm{N}-\mathrm{C}-\mathrm{NH}_{2} \\
\quad \| \\
\mathrm{NO} & \mathrm{O}
\end{array}
$$

Taking into account the effectiveness of the effect of mutagenic factors on mandarin seeds, as well as the specifics of the experiment, there have been used mutagen solutions with different concentrations $(0.2 \% ; 0.1 \%$; $0.08 \%$; $0.06 \% 0.05 \%$ ), within 24 -hour exposure. Treatment of the seed by the mutagen was made according to the appropriate methods (Zoz, 1968).

Seeds were removed from the fruit just before sowing. The separated seeds were dried in the air within 3 days, and then the dried seeds were put in gauze bags and placed in a mutagenic solution with different concentrations, the volume of which 15 times exceeded one of the seeds.

The utensil with seeds was covered tightly with a lid and left for 24 hours. After the mutagens affect completion the seeds were washed in the running water for 2-3 hours, and then they were sown in special seedboxes. To get seedlings, the controlling options (Control 2) were processed in distilled water. After that, the seeds were being dried at room temperature within 10 hours and then placed in boxes for sowing. After the vegetation period, the young seedlings 
were planted in the open ground next to the control plants, and the similar agrotechnical measures were carried out with them.

For the experiment, up to 100 mutant forms were obtained; among them 13 mutant forms were selected for the study of biochemical components, taking into account the concentration of the mutagen solution. Samples from all mutant forms were taken for analysis from the collection site of citrus fruits at the same time, during the same period. Biochemical analysis was performed 5 years after the entry into harvesting.

Phenolic compounds were high in high-pressure liquid chromatographic methods; The dry substance in the fruit juice was determined by a digital refractometer at $20^{\circ} \mathrm{C}$, while in the whole fruit - by the drying method. Phenolic compounds were determined by high-pressure liquid chromatographic methods; Antioxidant activity in the citrus fruit was determined by DPPH, by the method of joining free radicals (2.2 diphenyl- 1 pyricylhydride), calculated according to the percentage of DPPH inhibition of the free radical (Okava et al., 2001, Mensor et al., 2000, Burin et al., 2010, Miller et al., 1993). Phenolic compounds have been identified by ACQUITY-H, UPLC-PDA, MS, column BEN HSS $(100 \times 2.1 \mathrm{~mm} 1.7 \mu \mathrm{m})$. mobile phase $0.1 \%$ Formic acid in DW (A), $0.1 \%$ Formic acid in acetonitrile (B), gradient solvent $B$ gradient elution from $1 \% \mathrm{~B}$ for $1.5 \mathrm{~min}$ to reach $30 \% \mathrm{~B}$ at $14 \mathrm{~min}, 95 \% \mathrm{~B}$ at 16.5 to $17.5 \mathrm{~min}$ and $1 \%$ at 18 to $20 \mathrm{~min}$.

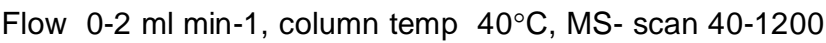
da, Probe $600^{\circ} \mathrm{C}$, Positive 0,8 kV, Capilari 1,5 kV, CV -15, PDA scan 210-500 nm.

\section{RESULTS AND DISCUSSION}

Phenolic compounds constitute a large group of secondary plant products with an aromatic ring bearing one or more hydroxyl substituents. Phenolic acids are one major class of phenolic compounds found widely in citrus fruits. The study of the content of common phenolic compounds was conducted separately in the skin, pulp and juice of the fetus. The analysis of the studied sample deals with the number of flavonoides, which is especially large in the citrus peel (Table 1). If the total number of phenolic compounds in the skin of the Unshiu mandarin (Control 1) is $560.26 \mathrm{mg} / 100 \mathrm{~g}$ on the raw mass, then in the seedling of the Unshiu mandarine (Control 2) it is quite low $-366.3 \mathrm{mg} / 100 \mathrm{~g}$ on the raw mass. The number of phenolic compounds in the skin of the mutant forms varies in the wide range (from $223.4 \mathrm{mg} / 100 \mathrm{~g}$ to $640.3 \mathrm{mg} / 100 \mathrm{~g}$ ) and in some mutant form $($ №314; 316$)$ it is almost 2 times more than in the Unshiu seedling (Control 2). Among the mutant forms the highest indicators of common phenolic compounds is in the fruit skin of the following forms: №314 (640.225 mg/100 g), №316 $(604.3 \mathrm{mg} / 100 \mathrm{~g})$ №343 (552.19 mg/100 g), №339 (549.7 $\mathrm{mg} / 100 \mathrm{~g})$, №318 (523.4 mg/100 g), №312 (527.61 mg/100 g), while the lowest ones were recorded in the forms №349 (223.4 mg/100 g), №345 (315.4 mg/100 g), №306 (346.22 $\mathrm{mg} / 100 \mathrm{~g})$.

If we compare the number of phenolic compounds separately in the pulp and the juice, it can be seen that in the forms with the high level of phenolic compounds, this indicator is also high in the pulp and the juice and vice versa, the forms with the low number of phenolic compounds have a respectively low number of them in the pulp and the juice.

Among the phenolic compounds, the mandarine fruit contains a large number of flavonoids, which, like common phenolic compounds, have high indicators in the skin, relatively low ones in the pulp and the lowest ones in the juice. The highest number of these compounds $(341.29 \mathrm{mg} /$ $100 \mathrm{~g}$ on the raw mass) was observed in the skin of the mandarin Unshiu (Control 1), in the juice - $9.83 \mathrm{mg} / 100 \mathrm{~g}$ on the raw mass and $49.23 \mathrm{mg} / 100 \mathrm{~g}$ in the pulp. The number

Table 1: Content of phenolic compounds in mutant forms of mandarin.

\begin{tabular}{lcccc}
\hline \multirow{2}{*}{ Sample name № } & $\begin{array}{c}\text { Mutagen solution } \\
\text { concentration, \% }\end{array}$ & \multicolumn{2}{c}{ Common phenolic compounds of $100 \mathrm{mg} / \mathrm{g}$ raw mass } \\
\cline { 2 - 5 } & 0.05 & 51.18 & Skin & Pulp \\
\hline 305 & 0.08 & 59.58 & 322.9 & 196.6 \\
306 & 0.08 & 55.68 & 527.61 & 185.41 \\
312 & 0.05 & 96.43 & 640.25 & 183.62 \\
314 & 0.08 & 72.92 & 522.3 & 320.29 \\
315 & 0.06 & 81.32 & 604.3 & 245.8 \\
316 & 0.06 & 62.72 & 523.4 & 250.5 \\
318 & 0.08 & 47.84 & 438.4 & 197.6 \\
336 & 0.2 & 63.02 & 549.7 & 193.0 \\
339 & 0.05 & 77.22 & 552.19 & 220.4 \\
343 & 0.1 & 31.86 & 315.4 & 260.23 \\
345 & 0.08 & 42.44 & 223.4 & 170.4 \\
349 & 0.1 & 33.56 & 473.7 & 115.2 \\
346 & Control I & 19.82 & 560.26 & 162.0 \\
& Control II & 63.02 & 366.3 & 132.43 \\
& & & 196.8 \\
\hline
\end{tabular}


of flavonoids in the Unshiu mandarin seedling (Control 2) is lower $(219.0 \mathrm{mg} / 100 \mathrm{~g}$ in the skin, $107.7 \mathrm{mg} / 100 \mathrm{~g}$ in the pulp, $21.44 \mathrm{mg} / 100 \mathrm{~g}$ in the juice) than in the mandarin Unshiu. The results of the study (Table 2) show, that the mutagen's exposure expands the range of flavonoid variability; the number of flavonoids in the mutant forms is relatively lower than in the Unshiu mandarin (Control 1), however, it is quite variable and varies from $199.0 \mathrm{mg} / 100 \mathrm{~g}$ to $292.08 \mathrm{mg} / 100 \mathrm{~g}$ in $100 \mathrm{~g}$ of the fruit skin, from $107.0 \mathrm{mg} /$ $100 \mathrm{~g}$ to $188.7 \mathrm{mg} / 100 \mathrm{~g}$ in the pulp and from $12.25 \mathrm{mg} / 100 \mathrm{~g}$ to $30.04 \mathrm{mg} / 100 \mathrm{gr}$ in the juice. Among the mutant forms, the largest number of flavonoids is contained in the skin of the forms: №346, №312, №318; in the raw pulp of the forms: №336 (197.0 mg/100 g), №305 (188.7 mg/100 g), №306 $(157.97 \mathrm{mg} / 100 \mathrm{~g})$, while the lowest number of flavonoids is in the forms №349 (199.0 mg/100 g), №343 (210.51 mg/100 g).

It has been conducted the analysis of the qualitative and quantitative composition of the phenolic compounds in the fruit juice of the two mutant forms (№316; №339) and the mandarin Unshiu (Fig 1; Fig 2; Fig 3; Fig 4; Fig 5) and the following compounds were identified: Hesperidin $(\mathrm{m} / \mathrm{z}$ $\left(\mathrm{H}^{+}\right)$-609), Neohesperidin $\left(\mathrm{m} / \mathrm{z}^{-}\left(\mathrm{H}^{+-}\right) 609\right)$, Naringenin $\left(\mathrm{m} / \mathrm{z}^{-}\right.$ $\left(\mathrm{H}^{+}\right)$-579), Narirutin (m/z579), Rutin $\left(\mathrm{m} / \mathrm{z}^{-}\left(\mathrm{H}^{+}\right)\right.$595), 5'-dehydroxyhesperidin $\left(\mathrm{m} / \mathrm{z}^{-}\left(\mathrm{H}^{+}\right)-593\right)$.

Table 2: Content of flavonoid compounds in mutant forms of mandarin.

\begin{tabular}{|c|c|c|c|c|}
\hline \multirow[t]{2}{*}{ Sample name № } & \multirow{2}{*}{$\begin{array}{c}\text { Mutagen } \\
\text { solution } \\
\text { concentration, \% }\end{array}$} & \multicolumn{3}{|c|}{$\begin{array}{l}\text { Common phenolic compounds of } 100 \mathrm{mg} / \mathrm{g} \\
\text { raw mass }\end{array}$} \\
\hline & & Juice & Skin & Pulp \\
\hline 305 & 0.05 & 18.0 & 229.3 & 188.7 \\
\hline 306 & 0.08 & 20.29 & 278.11 & 157.97 \\
\hline 312 & 0.08 & 19.8 & 288.5 & 132.54 \\
\hline 314 & 0.05 & 21.15 & 263.12 & 148.09 \\
\hline 315 & 0.08 & 16.0 & 251.6 & 101.0 \\
\hline 316 & 0.06 & 14.2 & 254.9 & 139.0 \\
\hline 318 & 0.06 & 17.0 & 285.5 & 126.9 \\
\hline 336 & 0.08 & 12.25 & 231.0 & 197.0 \\
\hline 339 & 0.2 & 30.04 & 273.6 & 154.1 \\
\hline 343 & 0.05 & 16.93 & 210.51 & 118.48 \\
\hline 345 & 0.1 & 28.6 & 235.6 & 113.3 \\
\hline 349 & 0.08 & 26.7 & 199.0 & 112.0 \\
\hline \multirow[t]{3}{*}{346} & 0.1 & 16.8 & 292.08 & 129.9 \\
\hline & Control I & 9.83 & 341.29 & 49.23 \\
\hline & Control II & 21.44 & 219.0 & 107.7 \\
\hline
\end{tabular}

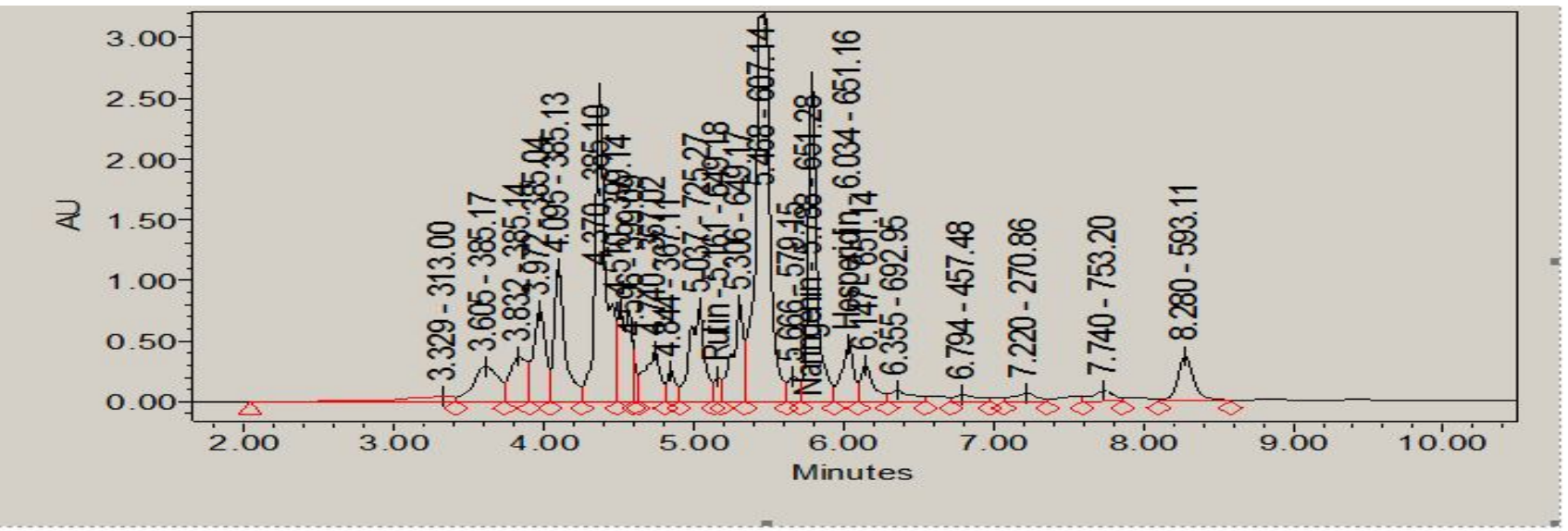

\begin{tabular}{|l|l|l|l|l|l|l|l|l|}
\hline & Name & Retention ime & Area & $\%$ Area & Height & Int Type & Amount & Units \\
\hline 1 & Rutin & 5.161 & 617067 & 0.66 & 201090 & VV & 72.5 & $\mathrm{mg} / \mathrm{L}$ \\
\hline 2 & Naringenin & 5.788 & 10938782 & 11.65 & 2625133 & $\mathrm{VV}$ & 817.5 & $\mathrm{mg} / 1$ \\
\hline 3 & Hesperidin & 6.034 & 2612397 & 2.78 & 468420 & $\mathrm{VV}$ & 122.5 & $\mathrm{mg} / 1$ \\
\hline
\end{tabular}

Fig 1: Chromatogram of Unshiu juice PDA. 
It has been studied the influence of a mutagen on antioxidant activity (Table 3). The table shows that antioxidant activity is especially high in the skin, then in the pulp and the juice. In the Unshiu mandarin (Control 1), the antioxidant activity of $21.22 \mathrm{mg}$ is enough for $50 \%$ inhibition of $\mathrm{DPPH}$ radical juice, while the lowest antioxidant activity $(51.77 \mathrm{mg})$ was recorded in the fetus juice of the Unshiu mandarin sowing (Control 2).

In the mutant forms, this indicator varies in a quite wide range (from $21.05 \mathrm{mg}$ to $39.39 \mathrm{mg}$ ). The highest antioxidant activity was revealed in the mutant forms №312 $(16,55 \mathrm{mg})$, №314 (18.69 mg), №318 (18.77 mg), №336 (19.20 mg). This indicator is lower in both control variants. Among the mutant forms, the lowest activity was revealed in forms №346 (50.51 $\mathrm{mg})$; №345 (46.91 mg), №349 (37.62 mg).

In this respect, the following mutant forms are distinguished with the highest activity: №312 $(8.75 \mathrm{mg})$, №305 (10.53 mg), №315 (11.2 mg) and these indicators are better than the ones of both Control Variants. As for the antioxidant activity in the pulp, it is correlated with the juice

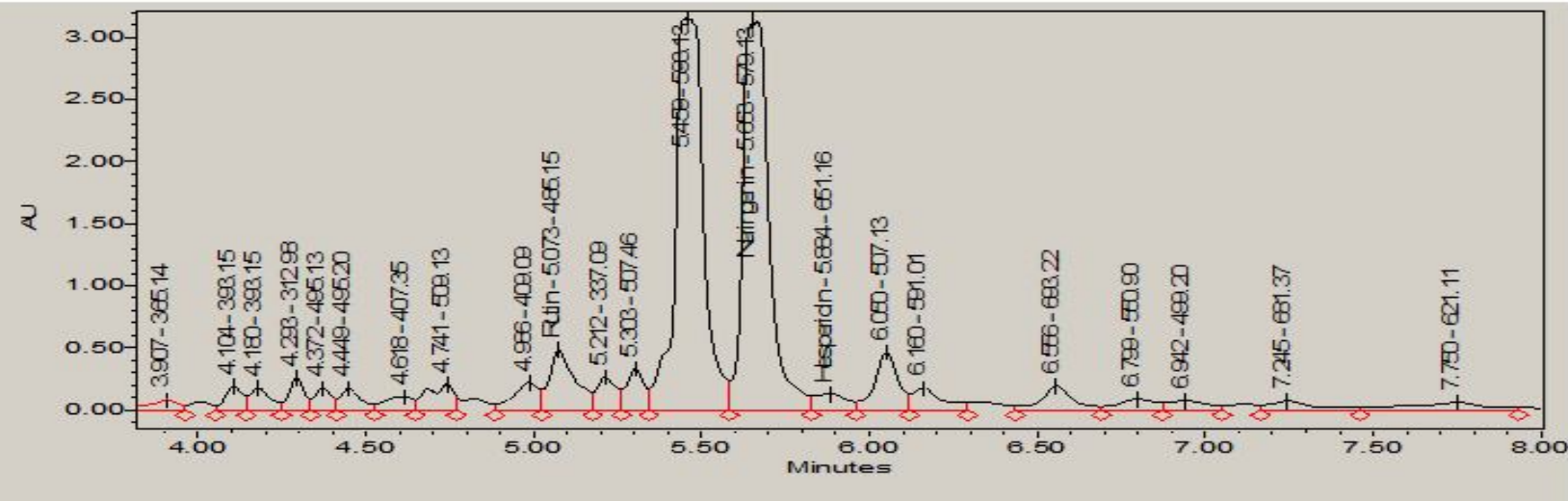

\begin{tabular}{|l|l|l|l|l|l|l|l|l|}
\hline & Name & Retention Time & Area & $\%$ Area & Height & Int Type & Amount & Units \\
\hline 1 & Rutin & 5.073 & 2541980 & 4.16 & 486303 & VV & 302,5 & $\mathrm{mg} / \mathrm{L}$ \\
\hline 2 & Naringenin & 5.653 & 17101354 & 27.99 & 3135917 & $\mathrm{VV}$ & 1277,5 & $\mathrm{mg} / 1$ \\
\hline 3 & Hesperidin & 5.884 & 857129 & 1.4 & 130070 & $\mathrm{VV}$ & 40,0 & $\mathrm{mg} / 1$ \\
\hline
\end{tabular}

Fig 2: Chromatogram of №316 juice PDA.

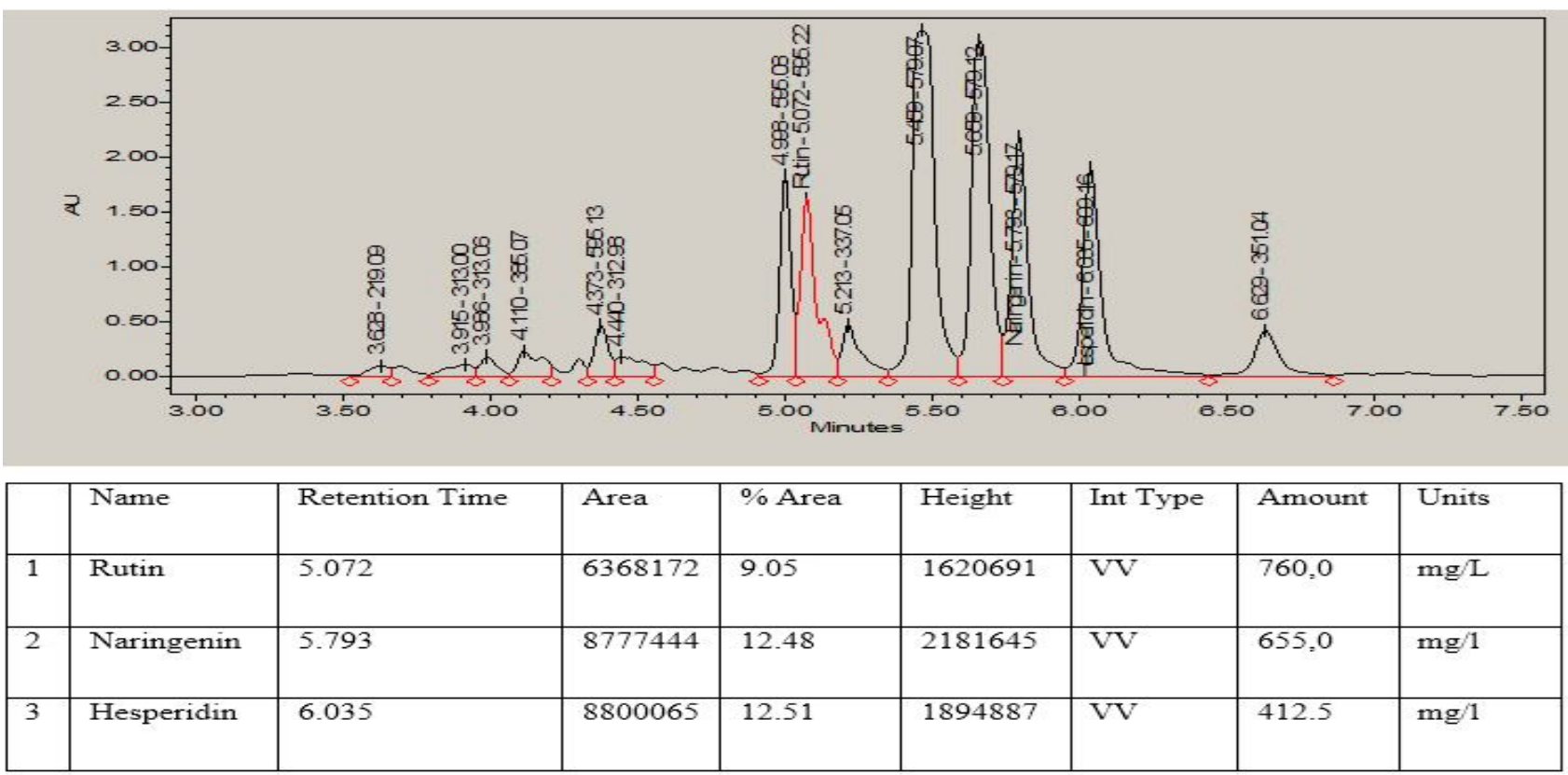

Fig 3: Chromatogram of №339 juice PDA. 
Table 3: Antioxidant activity in mutant forms of mandarin.

\begin{tabular}{lcccc}
\hline Sample name & $\begin{array}{c}\text { Mutagen } \\
\text { solution } \\
\text { concentration }\end{array}$ & \multicolumn{2}{c}{$\begin{array}{c}\text { Antioxidant activity } 0.1 \mathrm{mM} \text { DPPH 50\% inhibition } \\
\text { with mg of sample }\end{array}$} \\
\cline { 3 - 5 } 305 & 0.05 & Juice & Skin & Pulp \\
306 & 0.08 & 23.41 & 10.53 & 25.39 \\
312 & 0.08 & 16.83 & 19.71 & 25.66 \\
314 & 0.05 & 18.69 & 8.75 & 21.05 \\
315 & 0.08 & 19.91 & 15.51 & 29.31 \\
316 & 0.06 & 24.45 & 11.12 & 21.26 \\
318 & 0.06 & 18.77 & 22.01 & 26.13 \\
336 & 0.08 & 19.20 & 15.64 & 22.72 \\
339 & 0.2 & 20.36 & 14.08 & 28.12 \\
343 & 0.05 & 26.09 & 13.48 & 22.05 \\
345 & 0.1 & 46.91 & 14.86 & 31.26 \\
349 & 0.08 & 37.62 & 29.54 & 52.67 \\
346 & 0.1 & 50.51 & 25.7 & 39.39 \\
& Control & 21.22 & 29.53 & 57.84 \\
& Control II & 51.77 & 35.81 & 25.63 \\
\hline
\end{tabular}

indicators: The forms with high antioxidant activity in juice, have a high level of it in the pulp as well and vice versa.

If we compare the control variants, we can find out that the indicator of antioxidant activity $(50 \%$ inhibition of $0.1 \mathrm{mM}$ $\mathrm{DPPH}$ by $\mathrm{mg}$ sample) is usually higher $(21.22 \mathrm{mg})$ in the juice of the Unshiu mandarin (Control 1) than in the one (51.77 mg) of the Unshiu mandarin seedling (Control 2).

The data shows that antioxidant activity is relatively low with the use of mutagen solution of high concentration $(0.2 \%$; $0.1 \%$ ) and it approaches the indicator of the control variants or is relatively lower than it; however, in the cases of relatively low and moderate concentrations $(0.08 \%, 0.06 \%, 0.05 \%)$ with the use of mutagen solution, antioxidant activity gives a picture of a wider spectrum and it is relatively higher than in the control variants. Among the mutant forms, the ones with the high antioxidant activity (№312, №314, №315) were obtained in case of the use of mutagen solution of medium concentration $(0.08 \%, 0.06 \%, 0.05 \%)$, what indicates the fact that antioxidant activity appears to be the most sustainable and sensitive in case of exposure to medium concentration solution.

\section{CONCLUSION}

Such a wide range of biochemical components and diverse variation, found in the forms obtained by the effect of solutions of various concentrations of the chemical mutagen on the seeds of the Unshiu mandarin, indicates the fact that the tangerine type has a complex hybrid origin, which is influenced by many other types of citrus.

The analysis of the research results has shown that biochemical components are easily affected by mutagen and in most cases, it has a positive effect. The use of mutagen leads both to improvements in some biochemical components of mandarin fruits and to their deterioration; however, often an increase in the indicators of one feature leads to a decrease in another one, which ultimately leads to a change in the average common indicator.

If we compare the total number of phenolic compounds in the mutant forms and the control variants, then we will find out that the mutant forms are characterized by the higher indicators (except for some of them).

The results of the study show, that the mutagen's exposure expands the range of flavonoid variability; the number of flavonoids in the mutant forms is relatively lower than in the Unshiu mandarin.

It has been studied the influence of a mutagen on antioxidant activity. In the mutant forms, this indicator varies in a quite wide range (from $21.05 \mathrm{mg}$ to $39.39 \mathrm{mg}$ ). This indicator is lower in both control variants. The results of the study show that the effect of low and moderate concentrations of mutagen, unlike the high one, significantly expands the antioxidant activity.

The studies show that mutagen affects not only one of the selected genes but also the gene complex, which, in turn, makes chemical mutagenesis a powerful factor in changing the nature of a plant.

\section{REFERENCES}

Bermejo, A., Llosa, M. and Cano, A. (2011). Analysis of bioactive compounds in seven citrus cultivars. Food Science and Technology. 17(1): 55-62.

Cameron, J.W. and Frost, H.B. (1968). Genetics, Breeding and Nucellar Embryonic. Berkeley, CA: California. pp. 47-59.

Cottin, R. (2002). Citrus of the World. A Citrus Directory. SRA INRA CIRAD, San Giuliano. Version 2: pp. 62.

Del Caro Alessandra, Piga Antonio, Vacca Vincenzo and Agabbio Mario (2004). Changes of flavonoids, vitamin $C$ and antioxidant capacity in minimally processed citrus segments and juices during storage. Food Chemistry. 84: 99-105. 
Diasamidze, A.O. (1994). Natural and Chemical Mutagenesis in Citrus Breeding. Publishing Adjara, pp. 131.

Gil-Izquierdo, A., Gil, M.I., Ferreres, F. and Tomas-Barberan, F. (2001). In vitro availability of flavonoids and other phenolics in orange juice. Journal of Agriculture and Food Chemistry. 49: 1035-1041.

Goliadze, S.K. (1989). Chemical Mutagenesis of Citrus Breeding. Soviet Adjara. pp. 105.

Kerkadze, I.G. (1984). Induced mutation in subtropical groups. Aspects of the effects of chemical mutagens on the somatic tissues of citrus. Subtropical. Kulture. 5: 54-62.

Maluszynski, M., Nichterlein, K., Van Zanten and Ahloowalia B.S. (2000). Officially released mutant varieties. Plant Breeding and Genetics Section. 12: 1-11.

Masayoshi Sawamura, Nguyen Minh Tu, Yuji Onishi, Eriko Ogawa and Hyang-Sook Choi (2004). Characteristic odor components of Citrus reticulata Blanco cold-pressed Oil. Bioscience, Biotechnology and Biochemistry. 68(8): 1690-1697.

Micke, A.B., Donini, M. and Maluszynski, M. (1987). Induced mutations for crop impro-ve-m-ent review. Tropical Agriculture. 64: 259-272.
Okava, M., Kinjo, J., Nohara, T. and Ono, M. (2001). DPPH (1.1Diphenyl-2-Pierylhdrazyl) Ra-Dical Scavenging activity of flavonoids Obtained from Some Medical Plants. Biological and Pharmaceutical Bulletin. 24: 1202-1204.

Peterson, J.J., Beecher, G.R., Bhagwat, S.A., Dwyer, J.T., Gebhardt, S.E., Haytowitz, D.B. and Holden, J.M. (2006). Flavanones in grapefruit, lemons and limes. Journal of Food Composition and Analysis. 19: 74-80.

Sutarto, I.D., Agisimanto, D. and Supriyanto, A. (2009). Development of promising seedless citrus mutants through gamma irradiation. Induced Plant Mutations in the Genomics Era. 42: 306-308.

Tanaka, T. (1925). Further data on bud-variation in Citrus. Japanese Journal of Genetics. 3(3): 131-143.

Tomlekova, N.B. (2010). Induced Mutagenesis for Crop Improvement in Bulgaria. Plant Mutation Reports. 2: 4-28.

Watada, A.E., Abe, K. and Yamauchi, N. (1990). Physiological activities of partially processed fruits and vegetables. Food Technology. 20: 120-122.

Zoz, N.N. (1968). Method of using chemical mutagens in agricultural crop breeding. In Mutatsionnaya selektsiya [Mutation Breeding] (pp. 217-230). Moscow: Nauka. [in Russian] 